\title{
2018 Impact Factors Released for TMS Journals; New ICME Award;TMS Members Honored by MetSoc \\ themagazine
}
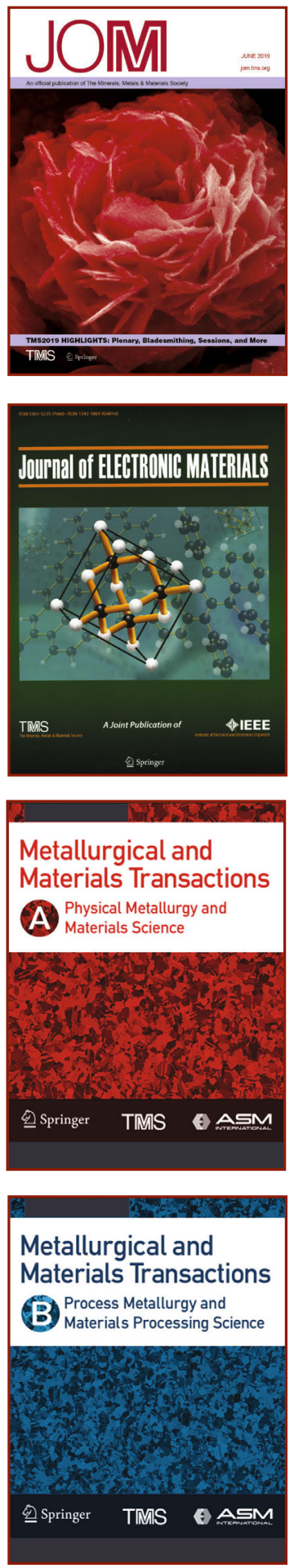

\section{Impact Factors Increase for TMS Journals}

The Impact Factors (IF) for TMS's four long-established journals continue their upward trend with the recent release of the 2018 Journal Citation Reports (Clarivate Analytics, 2019).

Impact Factor is the average number of citations counted in a given Impact Factor year for articles published in the two preceding years. It is based on the number by the number of citable articles published by that journal. Authors often refer to the IF of a journal for guidance when seeking to maximize exposure of their work.

What follows are the 2018 numbers for each journal (with 2017 numbers in parentheses): of citations of a journal's content divided
- JOM: 2.305 (2.145)

- Journal of Electronic Materials: 1.676 (1.566)

- Metallurgical and Materials Transactions A: 1.985 (1.887)

- Metallurgical and Materials Transactions B: 1.952 (1.834)

While IF can vary from year to year for a variety of reasons, TMS journals have generally tracked in a positive direction (see Figure 1), and also have achieved strong placement in Clarivate's ranking by subject categories (see Table I).

To access TMS's entire library of journals, visit the Journals section within the Publications tab on the TMS website at www.tms.org. Through this portal, TMS

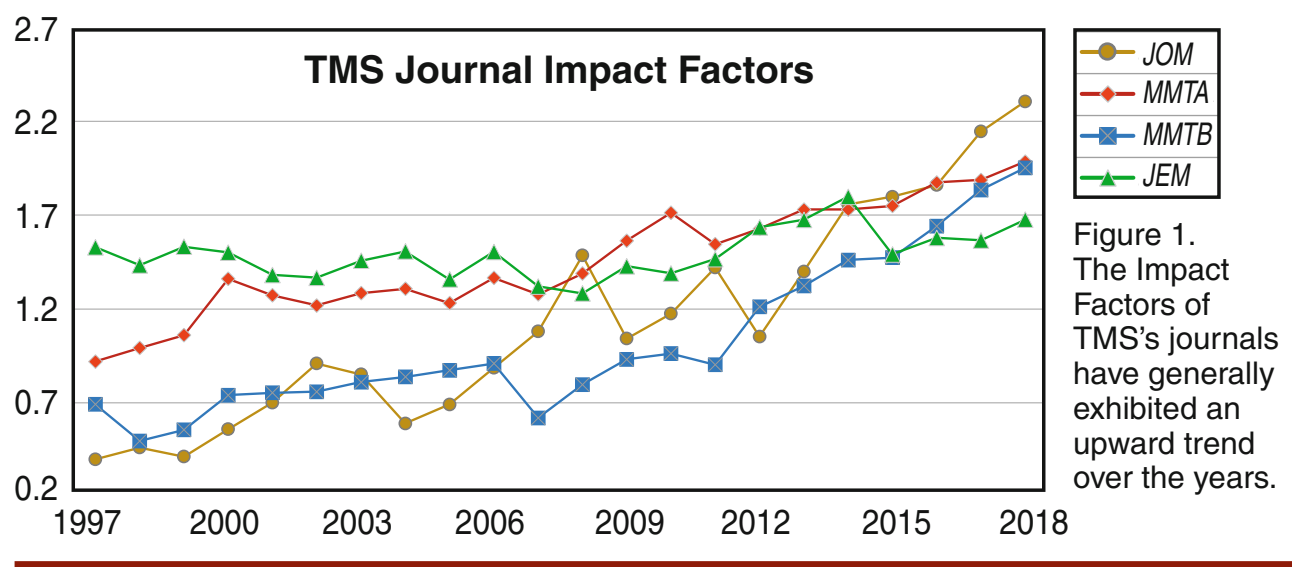

Table I: TMS Journal Rank by Subject Category

\begin{tabular}{|c|c|c|c|c|c|}
\hline Category Name & $\begin{array}{c}\text { Total } \\
\text { Journals } \\
2018\end{array}$ & JOM & MMTA & MMTB & JEM \\
\hline Materials Science, Multidisciplinary & 293 & 142 & 163 & 169 & 195 \\
\hline Metallurgy \& Metallurgical Engineering & 76 & 17 & 19 & 20 & - \\
\hline Mineralogy & 29 & 11 & - & - & - \\
\hline Mining \& Mineral Processing & 19 & 5 & - & - & - \\
\hline Engineering, Electrical \& Electronic & 265 & - & - & - & 162 \\
\hline Physics, Applied & 148 & - & - & - & 85 \\
\hline
\end{tabular}

Table I. This table presents all the subject categories assigned to TMS journals, as well as the rank of TMS journals within these categories. 
members have free access to current and archived issues of all TMS journals as well as 20 other materials-related journals published by Springer. Remember to first $\log$ in to the TMS website and then select the journal that you wish to read.

\section{New ICME Award from TMS}

\section{TMS's new ICME Industry}

Implementation Award recognizes the significant achievements that industry has made to implement integrated computational materials engineering (ICME) methods into a manufacturing process and/or design of a new material. This division-level award is sponsored by the TMS Materials Processing \& Manufacturing Division. It will be awarded every two years at the ICME World Congress, where award recipients will be honored with a keynote presentation at that year's meeting, along with a complimentary registration.

Individuals or teams interested in applying should demonstrate the implementation of an ICME process that integrates computational and experimental methods across at least two length and/ or time scales to accelerate the design and/or optimization of new material and/ or manufacturing process. Impact of the implementation should have been made public within the last five years of the nomination.

Applications must be submitted to awards@tms.org by April 1, 2020, to be considered for the 2021 award. Visit awards.tms.org for a complete list of award criteria and for more information on applying.

\section{TMS Members Receive MetSoc Awards}

Congratulations to the following TMS members for being honored by The Metallurgy \& Materials Society (MetSoc) of the Canadian Institute of Mining, Metallurgy and Petroleum (CIM). The awards were presented at the MetSoc Awards Banquet on August 20, during the 2019 Conference of Metallurgists (COM 2019) in Vancouver.

\section{Silver Medal \\ Boyd Davis}

Principal, Kingston Process Metallurgy Inc.

TMS member since 1999

The Silver Medal recognizes an individual who has contributed over a long period of time to the growth of MetSoc.

\section{MetSoc Brimacombe Award Hatem Zurob \\ Professor and Chair, Department of Materials Science and Engineering, McMaster University \\ TMS member since 1996}

The Brimacombe Award recognizes young achievers who have made noteworthy contributions in any of the scientific and technological disciplines relevant to MetSoc.

\section{MetSoc Award for Research Excellence, sponsored by Rio Tinto \\ Hani Henein \\ Professor, Alberta University TMS member since 1981}

MetSoc's highest honor for metallurgical contribution by an academic or research scientists in a Canadian research laboratory or Canadian university, this award recognizes lifetime achievement in teaching and research resulting in significant metallurgical developments.

\section{MetSoc Masters Scholarship Justin Plante \\ Student, Université Laval \\ TMS member since 2016 \\ The MetSoc Masters Scholarship encourages and supports the attainment of educational goals by masters' students who have demonstrated a high level of academic achievement at a Canadian university.}

\section{member news}

Share the good news about your professional accomplishments! Contact Kaitlin Calva, JOM Magazine Managing Editor, at kcalva@tms.org. Please note that only news submitted by current TMS members will be considered.

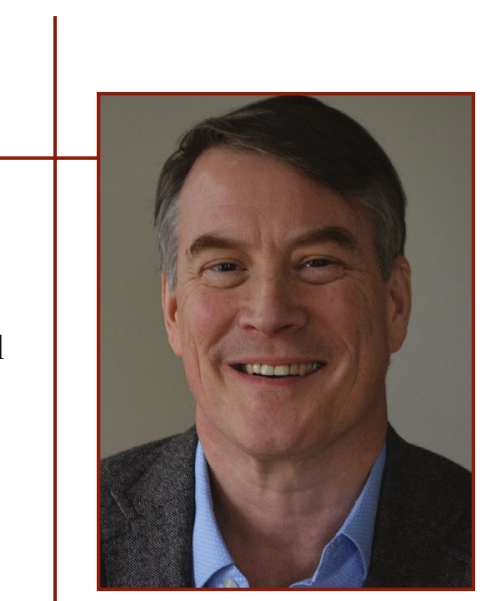

Boyd Davis

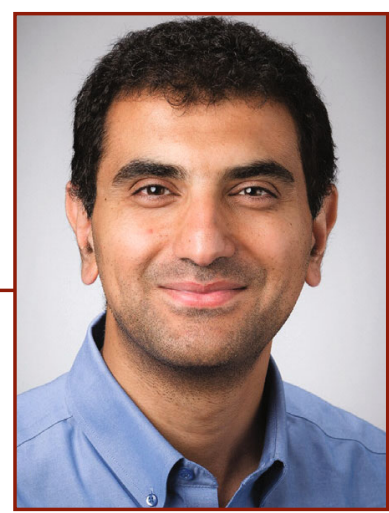

Hatem Zurob

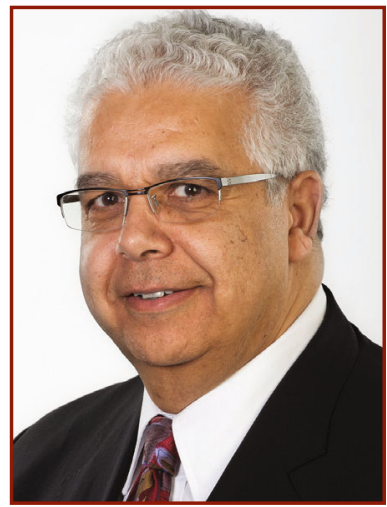

Hani Henein

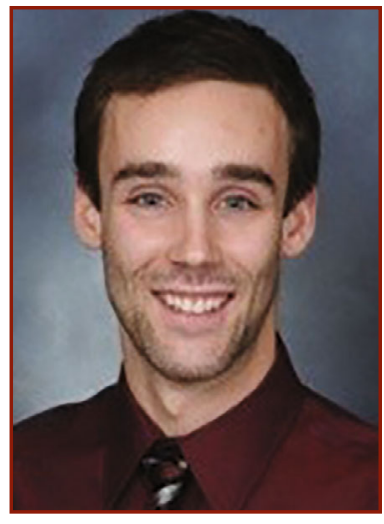

Justin Plante 